\title{
Optimisation and Just-in-Time
}

\author{
V. Beran
}

Arranging production activities to fit in with other construction activities is one of the basic ideas of the Just-in-Time approach. In the construction industry it has never been very fully applied. This is a mistake [1]. Construction works, particularly expensive parts of them, are a field where the approach can be and should be applied.

Keywords: Just-in-Time approach, production speeds, production volumes, optimisation savings, dependent capacity expansion, risk of extra costs.

\section{Introduction}

Organising construction activities according to the latest possible internal time schedule, taking into account the organisational and technological process, has been called the Just-in-Time method (JIT). This method has never been consistently applied in the construction industry, though this paper will argue that it should be. Finishing processes in construction production are an appropriate place for practicing JIT methods.

Two significant pillars of civil engineering, Tradition and Experience, have built a whole series of overt and covert myths into the civil engineering profession. Many of these relate to work organization. Some are useful and perpetuate the tradition and ethics of the profession, but many are outdated and no longer apply in the high-speed production conditions of modern construction.

This refers to the following principles:

1. To build quickly (under any circumstances) means to build economically.

2. A contract manager fulfilling the earliest possible deadline is a good contract manager.

3. To build continuously means to build economically.
4. Cumbersome technologies are disadvantageous.

5. Payment for work in progress is a good principle.

An important characteristic of a good contract manager has always been the ability to meet and fulfil deadlines. In other words, the agreed works should be completed before the deadline stated in the contract.

From the modern construction point of view, early completion may not be either necessary or economically useful. However the idea that what is completed can be counted on, has extraordinary strength in some areas of the construction industry. The efforts of many contract managers to create a time reserve and to lower the risk of breaching the construction deadline go so far as to perform a series of works earlier than is technologically and organizationally necessary. This tendency can be observed in numerous projects. A textbook example is the cooling towers of the Temelín nuclear power plant. In an effort to engage in expensive construction work (and to create time reserves for the future) the dominant construction feature during decades of construction was the cooling towers. Cooling towers are, however, technologically simple structures that should have been provided much later in the project. Nevertheless, they were the first technological structure to be erected on the site.

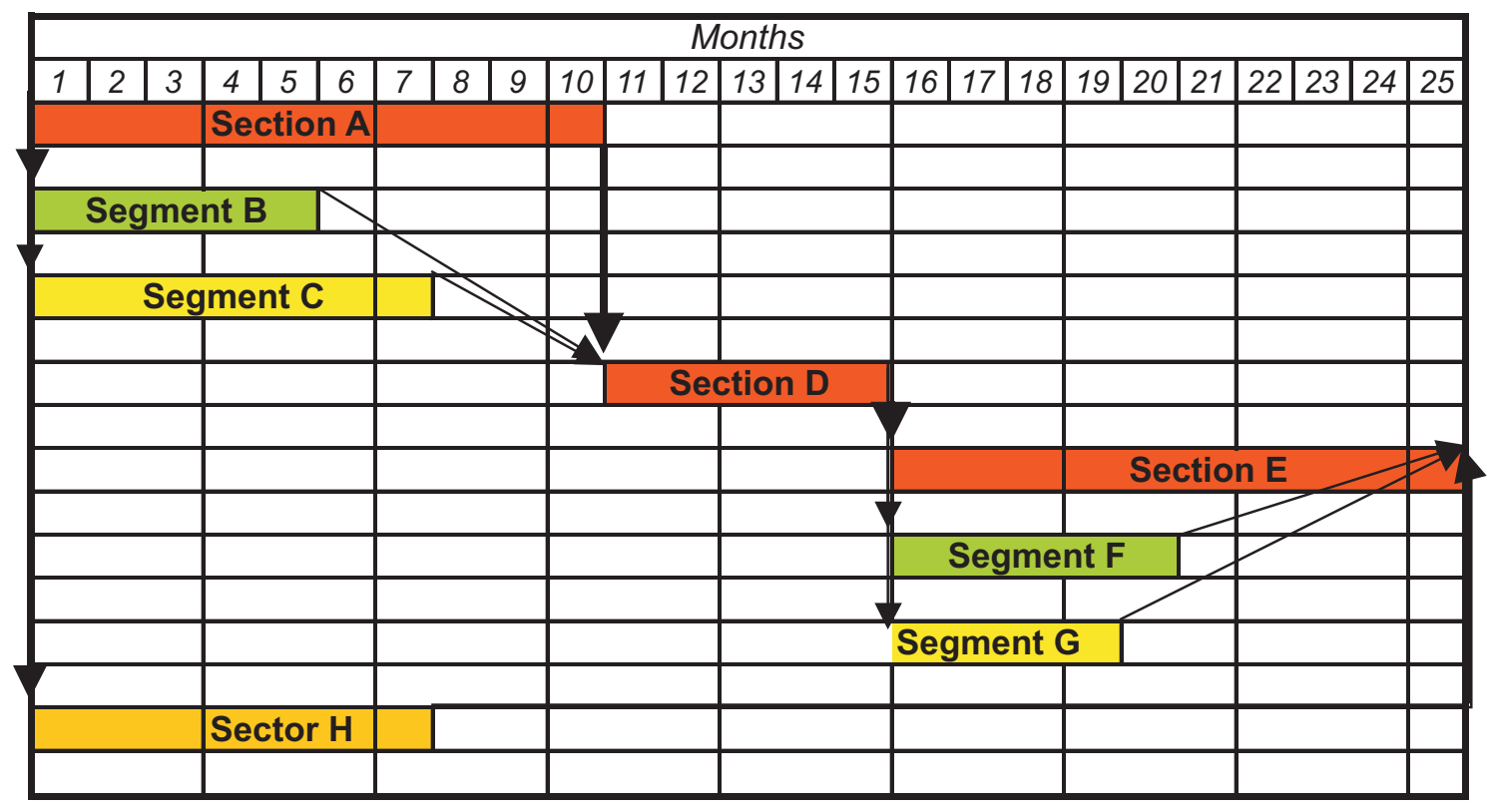

Fig. 1: Input project situation, organizational time layout structure 


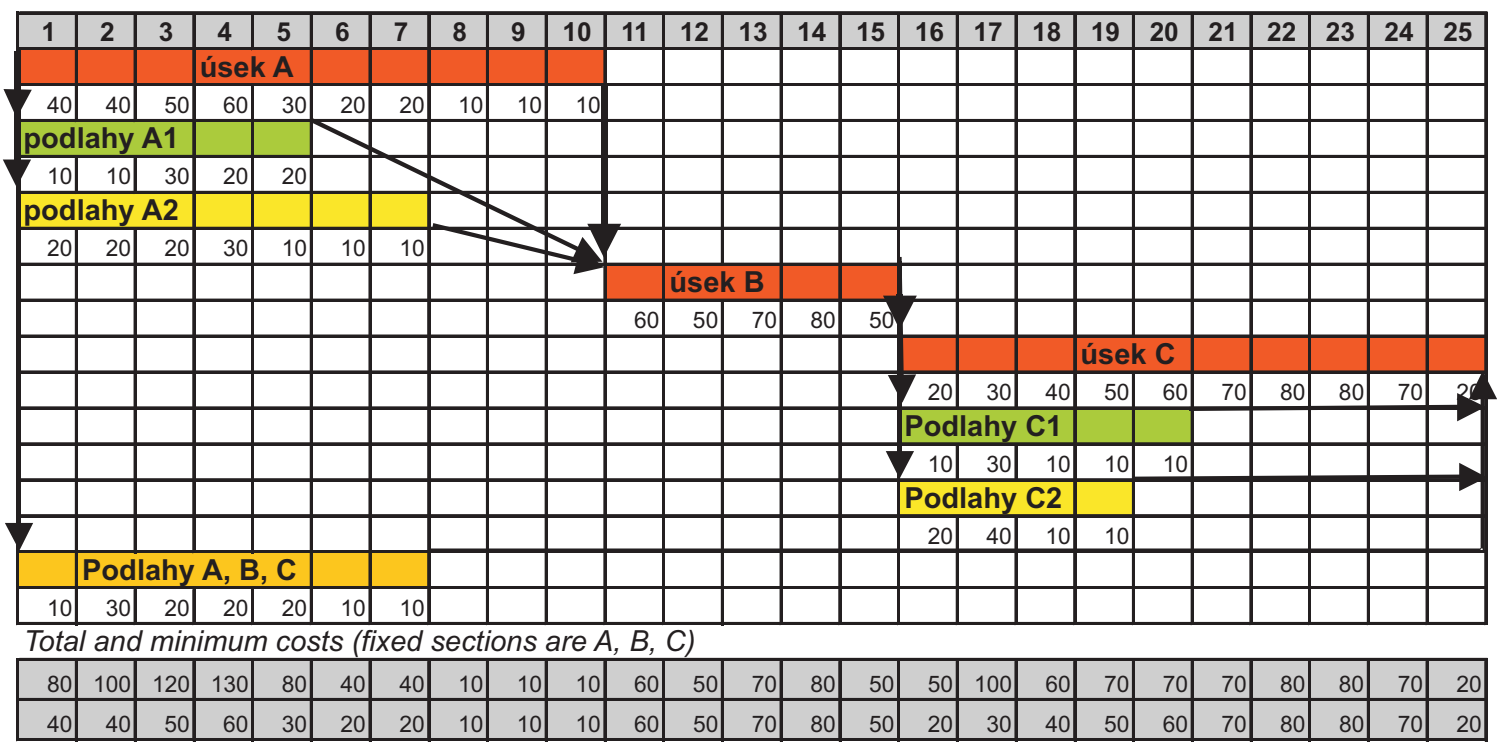

Fig. 2: Completed data, deadlines and costs for a reconstruction project

\section{Total and minimum costs}

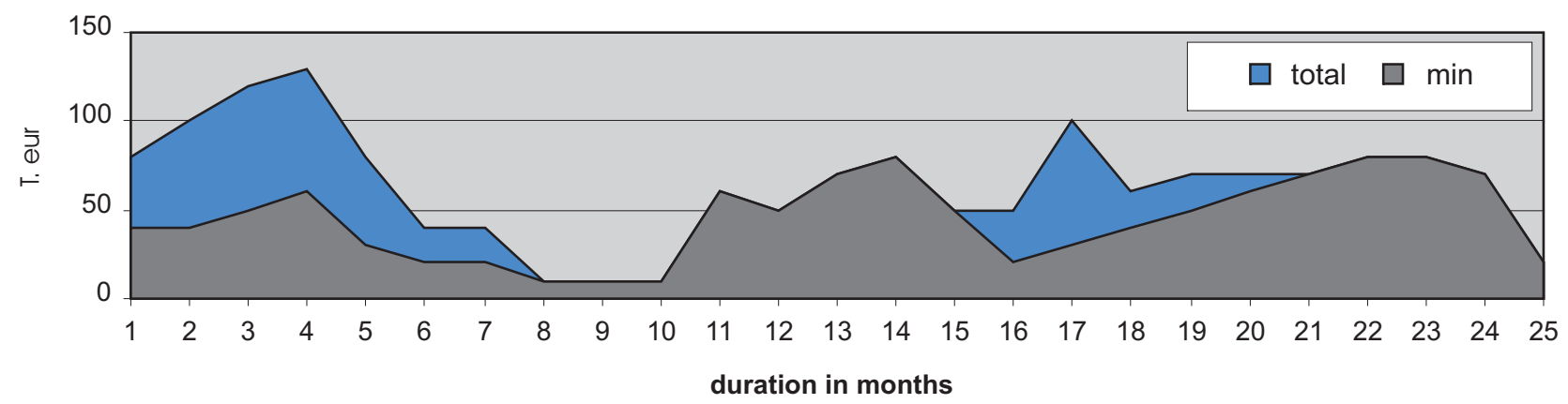

Fig. 3: Comparison of total and minimum costs (limited project schedule)

In the technologies and organizational processes for industrial buildings, railways and road reconstruction, public utilities and housing developments there are assembly procedures that are very appropriate for the given purpose. However, the cooling towers syndrome is also found here. The organisational process in the construction industry seems to favour extensively early completion of parts of a project. The application of JIT-type procedures would certainly be economically more suitable. Why does JIT enjoy so little popularity in the construction industry?

Let us put forward some of the main reasons, in no particular order:

a) low production speeds and large production volumes,

b) the need to create large work forces (number of workers and quantity of machinery on a building site) to complete a project (assembly, surfaces, greenery, pavements, etc.),

c) the preference for modest production technologies with low-cost material inputs,

d) reluctance of workers to adapt working practices and work hours to current construction needs,

e) reluctance of management to organise and pay for a special work regime in the final phases of construction (accommodation, shift work, transportation), f) low motivation of workers to re-train for new working practices and methods.

\section{Effect of JIT - what was the task like?}

Let us for a moment leave aside considerations, theories and detailed analysis. Let us direct our attention to a substantial economic problem. How can the possible effects of JIT be applied to the construction industry?

Let us assume that we are implementing and completing a simplified, extensive reconstruction of an administration building. The critical production activities can be divided into sections A, B, C (see Fig. 1). In addition to these activities, there are some production activities that may be freely movable (e.g., some finishing works such as surfaces/floors (pavements, puddles, underlying insulating layers), soundproofing, etc., vapour-and water-proofing, etc.) The possible schedules for these activities are graphically presented in the scheme in Fig. 2 (see the possible schedule for the segments inside the technological sections).

Let us now see (and evaluate) the overall effect of construction execution in calculating the cost of the necessary 


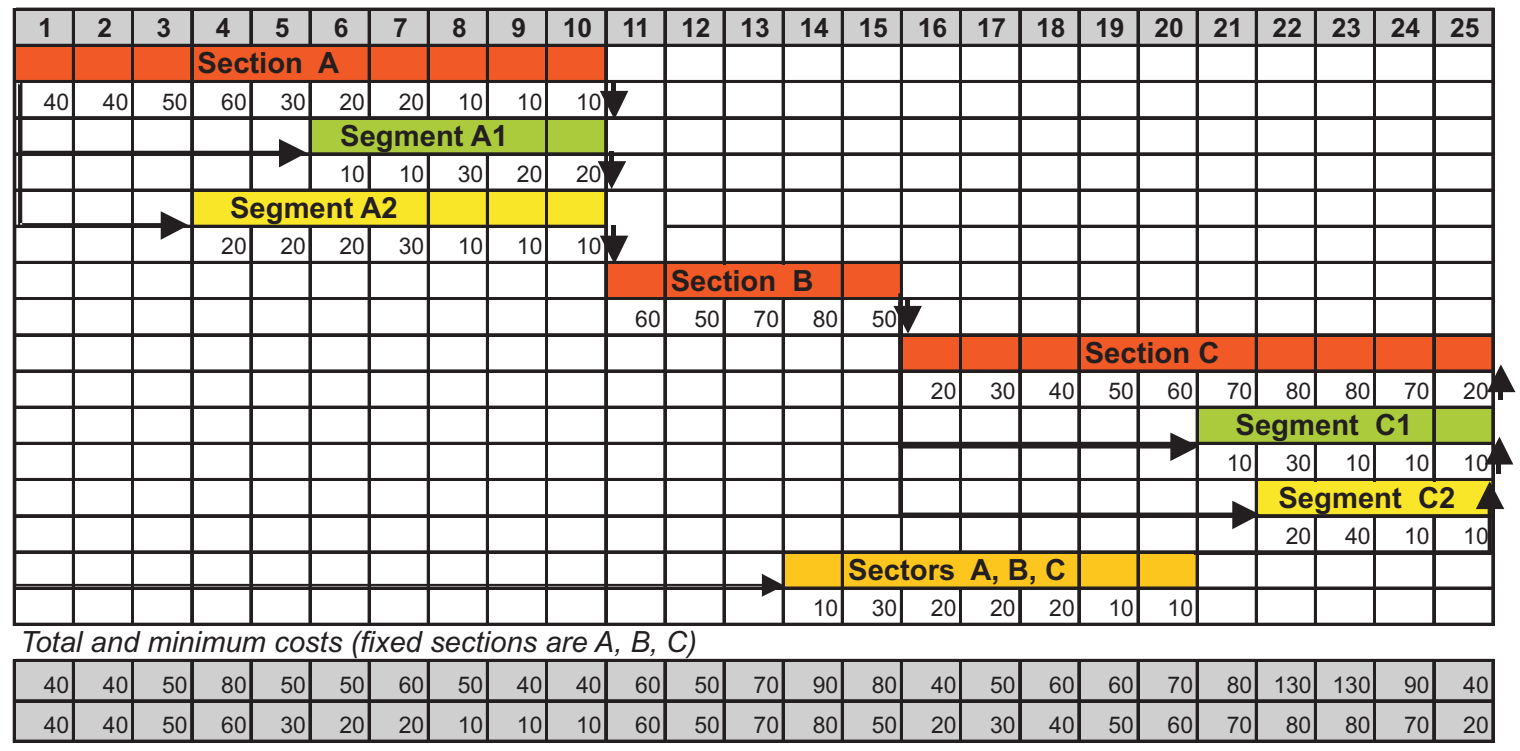

Fig. 4: Deadlines and costs for latest possible execution

operation credits for commonly carried out works as they were proposed. The time axis is given for calculation in months. For the sake of simplicity we assume that there will not be any delays in payments (in invoice payments, salary payments, payments to contractors and subcontractors). Fig. 3 provides fuller information about fixed and non-fixed construction capacities drawn in two separate lines. Changes in technology and in the organisation of the time schedule may be financially productive. However, the basic scheme is not very flexible in terms of time. We will investigate the advantages to be gained through optimisation under various conditions. Relocating the non-fixed activity segments may provide the first orientation.

A simple shift of production activities to the latest time limit is illustrated in Fig. 4. The production activities are carried out at the latest possible time. The final and most difficult opportunity for reducing the cost of the whole process of carrying out the construction work is through optimisation. Optimisation brings major savings (see Table 1). In the given case the deadlines and financial payments take into account some restricting conditions. One of these is the production speed of individual production activities, taking technological considerations into account. The aim was to minimise the costs, including interest payments, for completing the construction. The optimum solution is in many ways surprising. See Fig. 5 and compare the results with the calcu- lation tables in Fig. 2 (earliest possible execution) and Fig. 4 (latest possible execution). The total difference between the starting situation (Fig. 2) and the solution in an empirical shift to the latest possible deadlines is relatively low $1.89 \%$. Sophisticated changes, using optimisation, lead to a radical drop in the total costs $(6.17 \%)$. Even if not all gains can be achieved in practice, there is a range of possible managerial manipulation that could, if skilfully exploited, produce cost savings.

Note:

Each optimisation can lead to further possible improvements in the solutions, and can show which production sources (limits) incorporated into the restricting conditions will limit further improvements of the solution.

A more detailed analysis can show under what conditions production sources (production speed) can be increased in such a way that further improvement of the solution can be achieved.

Let us compare the results in Fig. 5 with the non-optimised solution in Fig. 2, and let us look at Table 1, where columns 2 to 4 give the main parameters of the task in Figs. 2, 4 and 5.

a) Duration times are changed for all production activities.

b) Production speeds are changed in the course of execution for all production activities.

Table 1: Comparison of solutions

\begin{tabular}{|l|c|c|c|}
\hline Actions total (in mil. Kč) & $\begin{array}{c}\text { Earliest possible } \\
\text { deadlines }\end{array}$ & $\begin{array}{c}\text { Latest possible } \\
\text { deadlines }\end{array}$ & $\begin{array}{c}\text { Optimisation } \\
\text { of deadlines and speeds }\end{array}$ \\
\hline Total costs (without credits) & 1600 & 1600 & 1600 \\
\hline Total critical activities (without credits) & 1120 & 1120 & 1120 \\
\hline Including bank credits (rate 10\%) & 1849 & 1813 & 1735 \\
\hline Average production speed & 28.66 & 28.66 & 32.45 \\
\hline
\end{tabular}




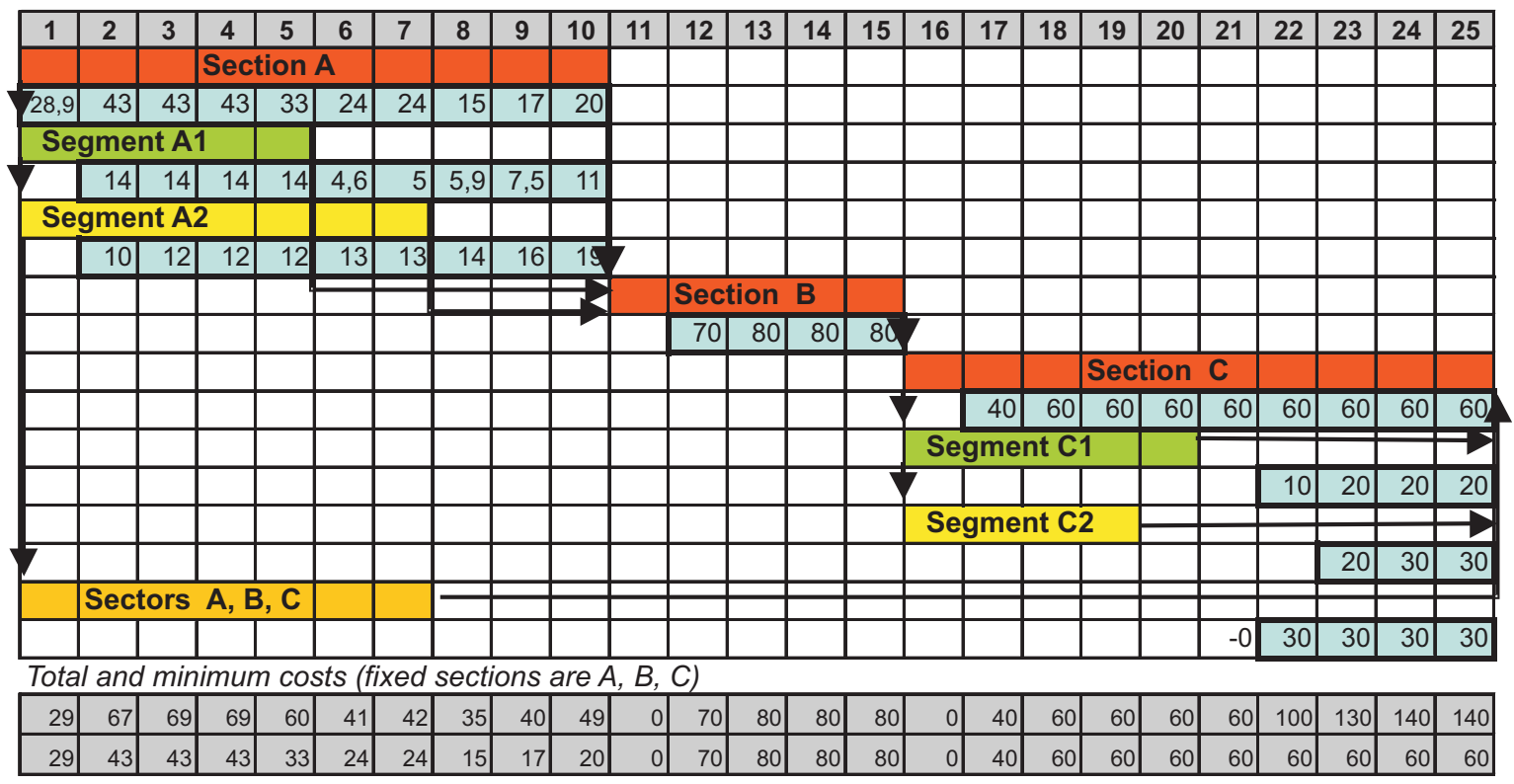

Fig. 5: Optimised deadlines and total cost of a construction project

c) The total duration of the construction work is changed (or the proposal to create new time reserves to cover risks in connections with production speed).

d) The main production processes will be speeded up, the duration of the project will be shorter.

e) The average production speed of the construction work increases from 28,6 to 32,4 thousands $€$ monthly, i.e., it increases to $113,2 \%$ of the original production speed.

f) A decrease in total costs to $93,83 \%$ in comparison with the initial solution (see Fig. 5 and proposed technological structure).

Other scenarios could also be presented. The main outcome of the whole task is an increase in production speeds and a reduction of time margins (floats). The overall effect is in essence a change in the organisation of project completion.

Most construction work is financed by credits. The contract is modified by regulations to the Commercial Code. This contract states that the creditor will provide funds up to the agreed amount in the benefit of the borrower. This contract requires the borrower to return the provided funds and to pay interest.

The major characteristic features of a credit are:

- the creditor's obligation to provide a borrower with funds on his request,

- the borrower's obligation to return the provided funds,

- the borrower's obligation to pay interest.

The outlined example shows a method for completing a floor (arrangements of surfaces and connecting parts of structures), i.e., technology that can substantially influence the final effect of the construction. A $6 \%$ reduction in the cost of a component, and its effect on the profitability of the project is a considerable argument and motivation for technological and organizational changes in the direction of JIT.

\section{A generalization of time dependent capacity expansion}

The problem of optimal capacity expansion of construction work as a time dependent problem has been studied in recent years in many different application contexts. Traditional capacity planning usually begins with a forecast of demand on the basis of organizational or technological needs. Planning and scheduling has for many years been the dominant approach in Central European management methodology. New approaches adopting a more productive methodology seem to be needed. Modern management of time dependent capacity expansion enables applications in production planning, strategic planning, inventory control, and network design. Applications in Telecommunications have been published by Laguna [4].

The time dependent capacity problem consists of finding the combination of activities $j(j=1,2, \ldots, N)$ with price $p_{j}$ and capacity $c_{\mathrm{j}}$, that should be employed in each time period $t(t=1, \ldots, T)$. The limitations are given by the total demand $D_{\mathrm{t}}$ at a minimum discounted cost.

Then, the problem becomes

$$
\min \sum_{t=1}^{T} \sum_{j=1}^{N} p_{\mathrm{j}} \gamma^{\mathrm{t}-1} x_{\mathrm{jt}}
$$

subject to

$$
\sum_{t=1}^{T} \sum_{j=1}^{N} c_{\mathrm{j}} x_{\mathrm{jt}} \geq D_{\mathrm{t}}
$$

for all $t$ where

$$
x_{\mathrm{jt}} \geq 0
$$

is production speed for all $j$ and $t$ and $\gamma$ is the discount factor $(0<\gamma<1)$ for $x_{\mathrm{jt}}$ for activities $j$ in time $t$. The structure of the capacity may be very variable. Table 2 shows a general 
example of this interpretation. Demand $D_{\mathrm{t}}$ may be structured not only as to $t$ as a particular time period, but also to demand blocks related to different activities $j$ and even to blocks of technologically or organizationally related activities.

Table 2: General scheme of a production structure

\begin{tabular}{|c|c|c|c|c|c|}
\hline & $t=1$ & $t=2$ & $t=3$ & $\ldots$ & $t=T$ \\
\hline Activity 1 & $x_{11}$ & $x_{12}$ & $x_{13}$ & $\ldots$ & $x_{1 \mathrm{~T}}$ \\
\hline Activity 2 & $x_{21}$ & $x_{22}$ & $x_{23}$ & $\ldots$ & $x_{2 \mathrm{~T}}$ \\
\hline & $\ldots$ & $\ldots$ & $\ldots$ & $\ldots$ & $\ldots$ \\
\hline Activity $N$ & $x_{\mathrm{N} 1}$ & $x_{\mathrm{N} 1}$ & $x_{\mathrm{N} 1}$ & $\ldots$ & $x_{\mathrm{N} 1}$ \\
\hline & $D_{1}$ & $D_{2}$ & $D_{3}$ & & $D_{\mathrm{T}}$ \\
\hline
\end{tabular}

If the matrix of variables in time $t$, where $t=(1,2,3, \ldots, T)$ is signed for particular scenarios $s$, where $s=(1,2, \ldots, S)$, say as $z_{\mathrm{ts}}$, the problem becomes

$$
\min F(\mathbf{x})=\sum_{t} \sum_{j} p_{j} \gamma^{\mathrm{t}-1} x_{\mathrm{jt}}+w \rho\left(\pi_{\mathrm{s}}, z_{\mathrm{ts}}\right)
$$

subject to

$$
\begin{array}{ll}
\sum_{t} \sum_{j} c_{j} x_{\mathrm{jt}}+z_{\mathrm{ts}} \geq D_{\mathrm{ts}} & \forall t, s, \\
x_{\mathrm{jt}} \in(0,1,2, \ldots) & \forall j, t, \\
z_{t s} \geq 0 & \forall t, s,
\end{array}
$$

where $w$ is the weighting factor and $\rho$ is the function of negative demand consequences related to the unmet demand $z_{\mathrm{jt}}$ and probability $\pi_{\mathrm{s}}$ in the range of scenario $s$.

Demand $D_{\text {ts }}$ will be presented with an uncertainty component $z_{\mathrm{jt}}$, see Eq. (5). This presents an imaginary demand associated with the risk of shortage of capacity with a probability $\pi_{\mathrm{s}}$ related to scenario $s$ at each period $t$. Function $\rho$ may take many forms. It usually reflects the risk attitude of the decision maker. The risk may be associated with the probability of shortage of capacity, the risk of extra costs or the risk of lack of quality if the production speed exceeds certain limits. Further applications and interpretations are possible.

\section{Conclusion}

The implementation of a technical project carried out in conditions of high production speeds and low time reserves requires changed technologies, organization and preparation of construction. In each specific case a civil engineer needs to know the economic impacts (capability of applicable calculation). The next important factor in the preparation and choice of management and organisation is the ability to calculate the risks inherent in the chosen technology [1], [2], [3]. It is obvious from the given illustrative example, which has the same features as the execution of a series of construction projects in recent years, that the myth of the importance of executing works in large volumes ahead of the deadlines has significant financial consequences. The interest rate applied here (10\%) is very low for current Czech business conditions, but may correspond to conditions of forthcoming recession in the current EU countries.

It is very probable that wherever construction work has been carried out at a loss or at a low profit, bad time and volume scheduling will have played a significant role in the bad economic results.

\section{Acknowledgment}

This paper originated as part of a CTU in Prague, Faculty of Civil Engineering research project on Management of sustainable development of the life cycle of buildings, building enterprises and territories (MSM: 210000006), financed by the Ministry of Education, Youth and Sports of ČR.

The calculations draw upon the methodological documents created within the project on Harmonisation of Engineering Activities with EU (proposal methods, implementation and life cycle of construction works according to EN ISO), funded by the Grant Agency of the Czech Republic, Prague 1, Národní Street 3 (GAČR).

\section{References}

[1] Beran, V.: Základy teorie rozhodování. [Foundations of decision theory]. Praha: Vydavatelství ČVUT v Praze, 1985.

[2] Beran, V., Macek, D.: Programové vybavení Balance Sensitivity. [Software]. Praha, 1998.

[3] Beran, V., Macek, D.: Programové vybavení Fault Cell. [Software]. Praha, 2000.

[4] Laguna, M.: Applying Robust Optimization to Capacity Expansion of One Location in Telecommunications with Demand Uncertainty. In Management Science, Vol. 44, No. 11, 1998.

[5] Mulvey, J. M., Vanderbei, R. J., Zenios A.: Robust optimisation of large scale Systems. Oper. Res. 43, 1995.

Doc. Ing. Václav Beran, DrSc.

e-mail: beran@fsv.cvut.cz

Department of Economics and Construction Management Czech Technical University in Prague

Faculty of Civil Engineering

Thákurova 7

16629 Praha 6, Czech Republic 